\title{
Tolerância à acidez e alumínio tóxico por isolados de rizóbios de solos no Amazonas, Brasil ${ }^{1}$
}

Aloisio Freitas CHAGAS JUNIOR ${ }^{2}$, Luiz Antonio de OLIVEIRA ${ }^{3}$, Arlen Nascimento de OLIVEIRA ${ }^{4}$

RESUMO

Com o objetivo de avaliar a tolerância à acidez e alumínio tóxico, isolados de rizóbio foram criados durante 15 dias em meio YMA com pH 6,5 (controle), $\mathrm{pH} 4,5$ e pH 4,5 + $\mathrm{Al}(2,0$ cmolc Al L-1). Entre os 200 isolados, 165 e 127 apresentaram tolerância aos 15 dias nos tratamento com pH 4,5 e pH 4,5 + Al, respectivamente. Destes, 29 apresentaram tolerância logo aos três dias de crescimento.

PALAVRAS-CHAVE: Ecologia microbiana, Bactérias fixadoras de N2, Amazônia.

\section{Tolerance to acidity and toxic aluminum of rhizobia isolated from soils in Amazonas, Brazil}

\section{ABSTRACT}

With the objective to evaluate toleranc to acidity and toxic aluminum, rhizobia isolates were grown for 15 days in YMA medium with pH 6.5 (control), $\mathrm{pH} 4.5$ and $\mathrm{pH} 4.5+\mathrm{Al}\left(2,0\right.$ cmolc Al L$\left.{ }^{-1}\right)$. Among the 200 isolates, 165 and 127 presented tolerance to the $15^{\text {th }}$ day in the treatments with $\mathrm{pH} 4,5$ and $\mathrm{pH} 4,5+\mathrm{Al}$, respectively. Of these, 29 presented tolerance by the third day of growth.

KEY WORDS: Microbial ecology, N2 fixation bacteria, Amazonia.

\footnotetext{
1 Parte da Tese de doutorado do primeiro autor. Pesquisa realizada com recursos do CNPq, Proc. № 474007/03-0 e da FAPEAM, Proc. No 624/04.

2 Dr. Universidade Federal do Tocantins - Campus de Gurupi, Caixa Postal 66, CEP: 77404-970, T0. E-mail: chagasjraf@bol.com.br

3 PhD. Pesquisador INPA-CPCA, Caixa Postal 478, CEP: 69011-970, AM. E-mail: luizoli@inpa.gov.br

${ }^{4}$ Universidade Federal do Amazonas. Manaus, AM. E-mail: arllem@yahoo.com.br
} 
A população de rizóbio pode ser diminuída por fatores predominantes nos solos da Amazônia, como o pH ácido e alumínio tóxico. A quantificação da tolerância à acidez e alumínio em laboratório pode ser o primeiro passo na seleção de isolados de rizóbio para esta região. Exemplos de tolerância a baixo $\mathrm{pH}$ de estirpes rizóbio foram reportados por Oliveira \& Magalhães (1999), mostrando que os testes de laboratório são significativos processos de seleção de estirpes tolerantes e eliminação daquelas estirpes que são sensíveis. Com respeito à seleção de rizóbio adaptáveis a solos ácidos, com os diversos fatores ligados à acidez ou dela decorrentes que variam de solo para solo, existe uma contínua necessidade da identificação de estirpes tolerantes à acidez e alumínio tóxico capazes de aumentar a produtividade de leguminosas. Assim, este trabalho objetivou avaliar em laboratório a tolerância à acidez e alumínio tóxico de isolados de rizóbio oriundos de solos de diferentes regiōes do Estado do Amazonas.

Foram utilizados 200 isolados obtidos da coleção do INPA (Instituto Nacional de Pesquisas da Amazônia), oriundos de solos da Amazônia. Os tratamentos utilizaram o meio YMA (Vincent, 1970) com pH 4,5, pH 4,5 + Al e pH 6,5 como controle, com quatro repetições cada. $\mathrm{O}$ alumínio foi adicionado na forma de $\mathrm{AlCl} 3$ para o tratamento $\mathrm{pH} 4,5+2,0$ cmolc (+) Al/L, para se obter a concentração de Al encontrada nas principais classes de solos da Amazônia, servindo, assim, como parâmetro para as condições reais deste elemento na natureza. Foi acrescentado o corante bromocresol verde (20 $\mathrm{mL} \mathrm{L}^{-1}$ ) nos meios com $\mathrm{pH} 4,5$ e $\mathrm{pH} 4,5+\mathrm{Al}$, e no meio com pH 6,5 foi adicionado o azul de bromotimol $\left(5 \mathrm{~mL} \mathrm{~L}^{-1}\right)$, com o objetivo de visualizar a alteração do $\mathrm{pH}$ do meio pelas bactérias, em função da alteração da cor do meio.

Foi utilizado o método de riscagem proposto por Oliveira \& Magalhães (1999). As avaliaçōes foram feitas a cada três dias durante um período de 15 dias, em condiçôes de laboratório a uma temperatura média de $28^{\circ} \mathrm{C}$. De acordo com o crescimento celular foi determinando o grau de tolerância dos isolados, sendo tolerantes isolados com crescimento médio acima de 3,06, tolerância moderada com crescimento entre 2,06 e 3,00 e sensível entre 1,00 e 2,00. O delineamento experimental foi o inteiramente ao acaso. Foi realizada análise de variância com teste $\mathrm{F}$ e teste de Tukey a $5 \%$, utilizando o programa STATISTICA 6.0.

Somente 29 isolados, dos 200 testados, apresentaram escores de crescimento tolerante (superior a 3,06) logo aos três dias de crescimento (Tabela 1). Entre estes isolados, nove apresentaram escore 4,00 a partir do terceiro e sexto dia. Segundo Graham et al. (1994), a tolerância ao $\mathrm{pH}$ ácido em rizóbio depende da habilidade em manter o $\mathrm{pH}$ intracelular entre 7,2 e 7,5 quando o pH externo é acido. O tempo de crescimento pode também ser usado para a seleção, pois os isolados que apresentaram escores superiores a 3,06 em menor período de tempo podem ser mais tolerantes ao baixo $\mathrm{pH}$. A acidez do meio também afetou o crescimento de isolados de rizóbio, como descrito por Hara \& Oliveira (2005), onde a proporção de isolados oriundos de solos ácidos, tolerantes á acidez foi baixa, em torno de $25 \%$.

Quanto ao tratamento com $\mathrm{pH} 4,5+\mathrm{Al}$, no terceiro dia de avaliação, foi observado máximo crescimento (escore $4,00)$ para o isolado INPA R1002, e no sexto dia para os isolados INPA R880, INPA R888, INPA R896, INPA R931, INPA R995, INPA R1002 e INPA R1005 (Tabela 1). Conseqüentemente, o tempo de crescimento pode também ser usado para a seleção quanto à tolerância ao Al. Ao longo das avaliações, a cada três dias houve aumento do número de isolados tolerantes aos meios com $\mathrm{pH} 4,5$ e pH 4,5+ Al, mostrando a ocorrência de adaptação às condiçôes iniciais do meio (Figura 1). Tem sido demonstrada melhor adaptação de bactérias à acidez quando previamente crescidas em meios de cultura levemente ácidos, fenômeno conhecido como "acid habituation" ou "adaptative tolerance response" (Dilworth et al., 1999).

Quanto à capacidade de acidificar ou alcalinizar, o meio com pH 6,5 foi acidificado por 187 isolados (93,5\%) (Figura 2). Entre estes isolados, 13 apresentaram escore de crescimento abaixo de 3,06, indicando que a diminuiçāo do $\mathrm{pH}$ pode estar afetando o crescimento dessas bactérias. Quanto aos isolados tolerantes à acidez, 66 foram capazes de alcalinizar ou não modificar a pH do meio ácido ( $\mathrm{pH} 4,5)$, o que pode ser considerado como um mecanismo de adaptação a essa condição de estresse. Segundo Barberi et al. (2004), a elevação do $\mathrm{pH}$ do meio é decorrente do metabolismo da bactéria que, ao atuar sobre o substrato em busca de energia, libera substâncias básicas que aumentam o pH externo. Para o meio com pH 4,5 $+\mathrm{Al}$, foi observado que 45 isolados alcalinizaram o meio, os quais apresentaram tolerância a esses fatores, com escore de crescimento maior que 3,06 (Figura 2). Foi verificada a diminuição do $\mathrm{pH}$ desse meio por 80 isolados tolerantes, sendo que, entre esses, 78 apresentaram tolerância tanto à acidez como ao alumínio.

Os isolados mais tolerantes à acidez e alumínio apresentamse como promissores. Estes isolados necessitam ser testados ainda em simbiose com a planta na presença destes fatores limitantes, uma vez que o objetivo é obter tolerância e eficiência a estes fatores na mesma estirpe. 


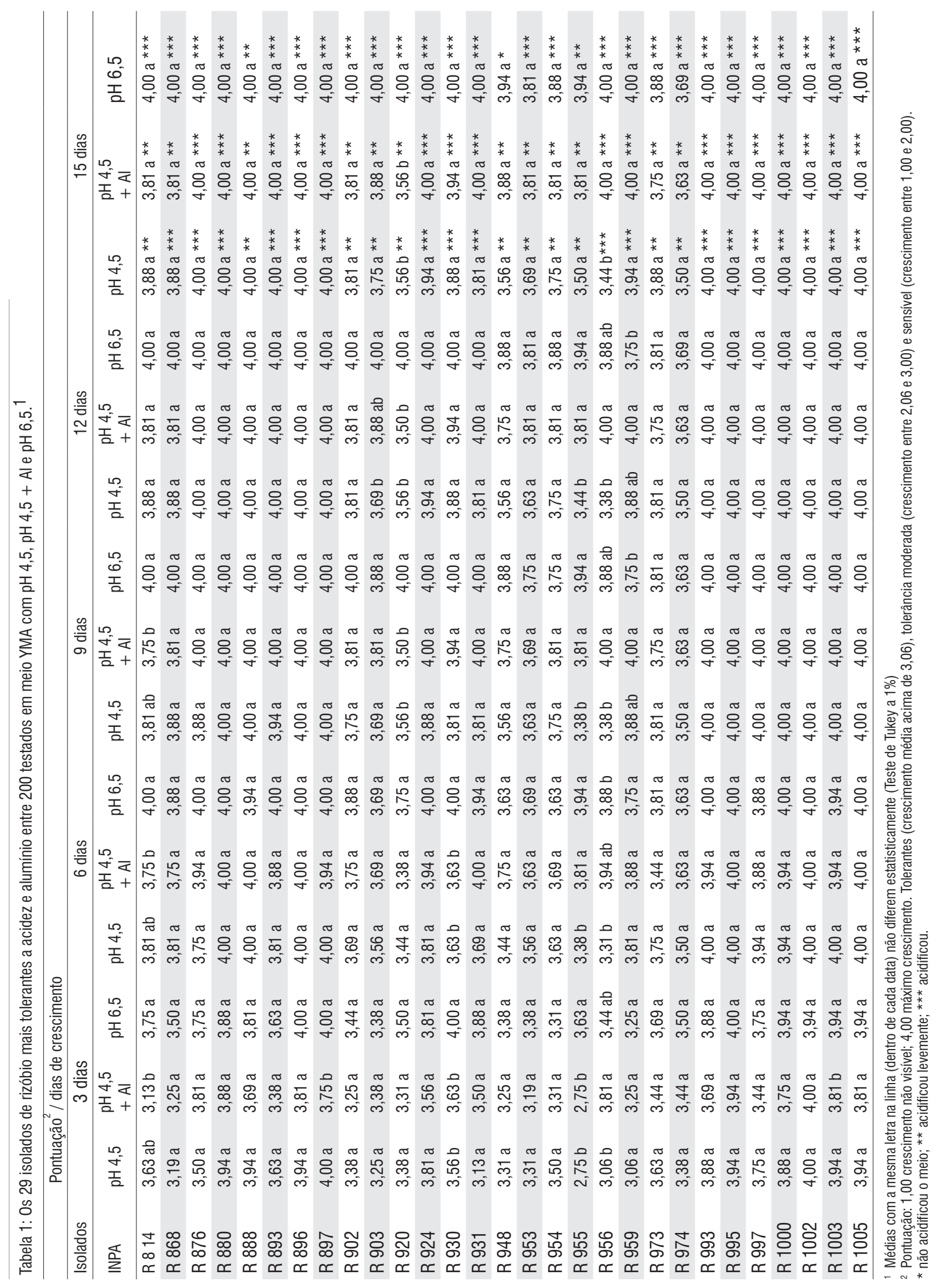



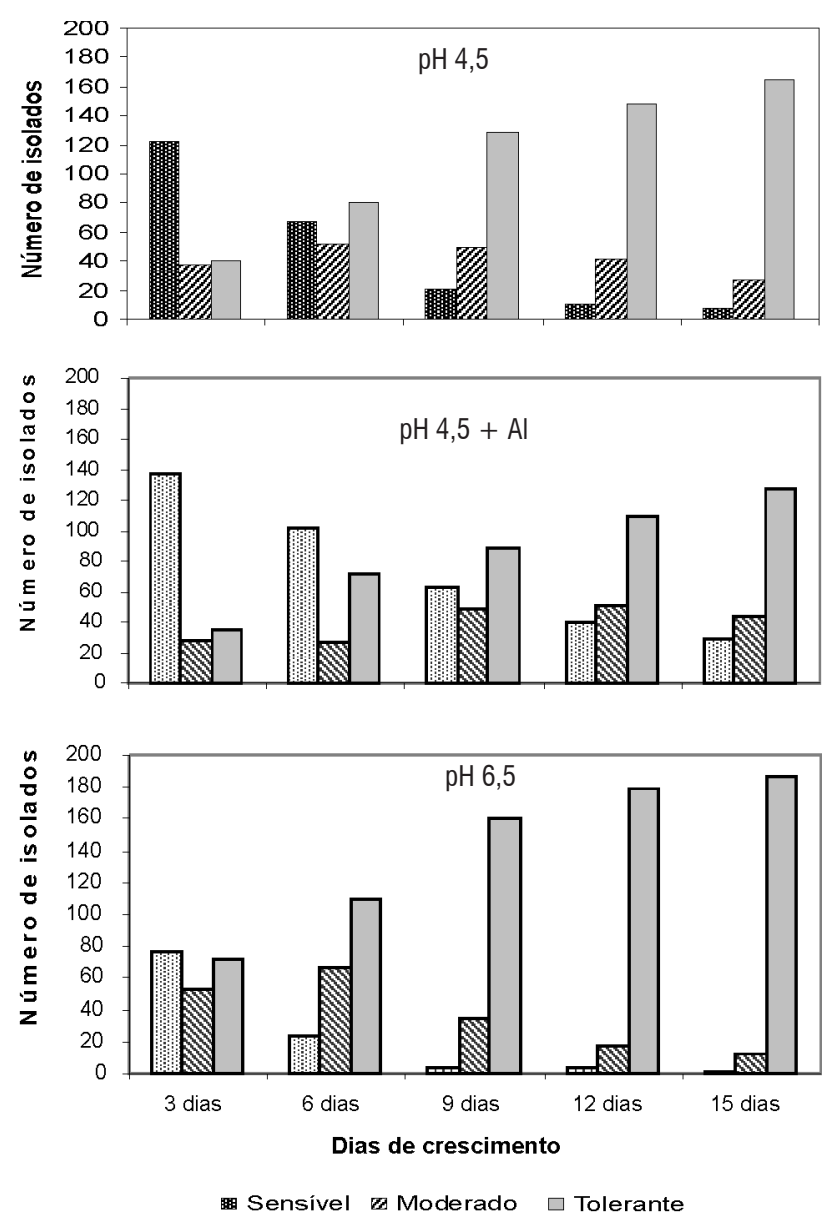

Figura 1 - Crescimento de isolados de rizóbio ao longo de 15 dias de avaliação em meios YMA com pH 6,5, pH 4,5 e pH 4,5 + Al

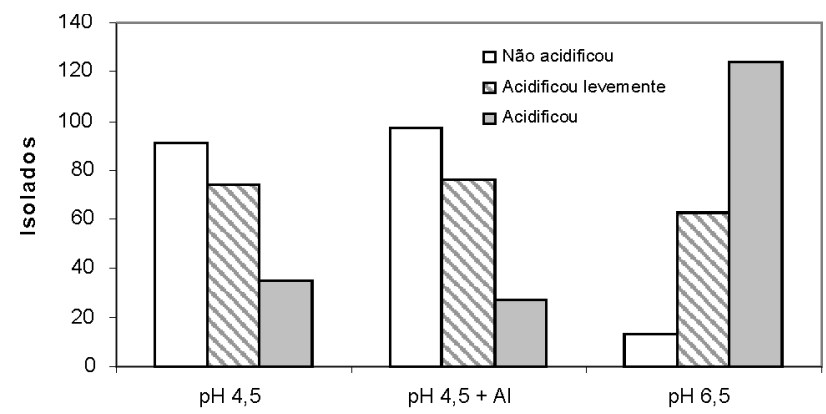

Figura 2 - Alteração do pH do meio pelos isolados de rizóbio, em função da alteração da cor do meio, após 15 dias de crescimento em meio YMA com bromocresol verde para pH 4,5 e pH 4,5 + Al e azul de bromotimol para $\mathrm{pH} 6,5$.

\section{AGRADECIMENTOS}

À CAPES pela concessão de Bolsa; à UFAM e INPA pelo espaço físico de laboratório e FAPEAM e CNPq pelos recursos financeiros que viabilizaram essa pesquisa.

\section{BIBLIOGRAFIA CITADA}

Barberi, A.; Moreira, F.M.S.; Florentino, L.A.; Rodrigues, M.I.D. 2004. Crescimento de Bradyrhizobium elkanii estirpe BR $29 \mathrm{em}$ meios de cultivo com diferentes valores de $\mathrm{pH}$ inicial. Ciência e Agrotecnologia, 28(2): 397-405.

Dilworth, M.J.; Rynne, F.G.; Castelli; Vivas-Marfisi, A.I.; Glenn, A.R. 1999. Survival and exopolysaccharide production in Sinorhizobium meliloti WSM419 are affected by calcium and low pH. Microbiology, 145(7): 1585-1593.

Graham, P.H.; Draeger, K.J.; Ferrey, M.L.; Conray, M.J.; Hammer, B.E.; Martinez, E.; Aarons, S.R.; Quintino, C. 1994. Acid pH tolerance in strains of Rhizobium and initial studies on the basis for acid tolerance of Rhizobium tropici UMR 1899. Canadian Journal of Microbiology, 40: 198-207.

Hara, F.A.S.; Oliveira, L.A. 2005. Características fisiológicas e ecológicas de isolados de rizóbios oriundos de solos ácidos de Iranduba, Amazonas. Pesquisa Agropecuária Brasileira, 40(7): 667-672.

Oliveira, L.A.; Magalhães, H.P. 1999. Quantitative evaluation of acidity tolerance of root nodule bacteria. Revista de Microbiologia, 30: 203-208.

Vincent, J. M. 1970. A manual for practical study of root nodule bacteria. IBP Handbook N. 15. Blackwell Scient. Publ., Oxford. 140 pp.

Recebido em 05/02/2007

Aceito em 24/07/2008 